\title{
Comparative Feeding and Digestive Performance of Four Lepidopteran Species of Larvae on Onion, Allium cepa var aggregatum L. as A Host Plant
}

\author{
R. Rubiya ${ }^{1}$, M. Murugan ${ }^{2 *}$, M. Shanthi ${ }^{1}$, V. Krishnamoorthi ${ }^{3}$ and S. Vellaikumar $^{4}$
}

${ }^{1}$ Department of Agricultural Entomology, Agricultural College and Research Institute, Tamil Nadu Agricultural University, Madurai - 625104, Tamil Nadu, India

${ }^{2}$ Department of Agricultural Entomology, Tamil Nadu Agricultural University, Coimbatore - 641003, Tamil Nadu, India

${ }^{3}$ Horticultural Research Station, Tamil Nadu Agricultural University, Thadiyankudisai, Perumparai - 624 212, Dindigul District, Tamil Nadu, India

${ }^{4}$ Department of Biotechnology, Agricultural College and Research Institute, Tamil Nadu Agricultural University, Madurai - 625104, Tamil Nadu, India

*Corresponding author

\section{Keywords}

Onion, Food consumption, Leaf feeding insect, Spodoptera exigua, Spodoptera litura, Helicoverpa armigera, Spodoptera frugiperda

Article Info

Accepted: 15 May 2019 Available Online: 10 June 2019

\section{A B S T R A C T}

Shallot, Allium cepa var aggregatum L. (Alliaceae) is one of the major bulbous vegetable grown both as garden and field crop in India. The major leaf feeding insect pests of onion, Spodoptera exigua, Spodoptera litura, Helicoverpa armigera and the recently invasive insect Spodoptera frugiperda were causing destructive damage to the plant and made economic yield loss. Food consumption indices were studied under laboratory condition at room temperature $28 \pm 2^{\circ} \mathrm{C}$ and it is one of the parameter to identify the damage potential of insects. The growth rate (GR) and Efficiency of Conversion of ingested food (ECI) was significantly different in third instar but fourth and fifth instar, they showed less significant difference or on par with each other. The high GR and Consumption Index (CI) was observed in S. exigua $(0.08 \mathrm{mg} / \mathrm{day}$ and $0.81 \mathrm{mg} /$ day respectively), Efficiency of Conversion of Digested food (ECD) $(12.76 \%)$ and ECI $(12.23 \%)$ was the highest in S. litura in third instar but in fourth instar the highest ECD (13.49\%) and ECI (10.34\%) was observed in S. frugiperda and no significant difference was noticed in fifth instar for ECI and ECD. The grand mean GR and CI was the highest in $S$. exigua $(0.06 \mathrm{mg} / \mathrm{day}),(6.82 \mathrm{mg} / \mathrm{day})$ and the $\mathrm{AD}$, ECD and ECI was the highest in H. armigera (93.68\%), S. frugiperda (10.59\%), S. litura (8.93\%) respectively. The lowest Consumption Rate (CR) and CI were observed in $S$. litura $(0.65 \mathrm{mg} /$ day and $2.27 \mathrm{mg} /$ day $)$, and ECD and ECI were noticed in $H$. armigera $(6.15 \%$ and $(5.77 \%)$. The results of food consumption indices had indicated that $S$. exigua followed by $H$. armigera caused more damage on shallot onion than the other two caterpillars studied but effective utilization of food was made by $S$. litura and $S$. frugiperda. 


\section{Introduction}

Shallot, Allium cepa var aggregatum L. (Alliaceae) is one of the major bulbous vegetable grown both as garden and field crop in India, a major edible species among the 700 species reported onions in the world (Shrestha, 2004).

Onion is a Latin word containing the meaning of one large pearl ('unio') and is considered "Jewel among vegetables" by Chinese owing to its nutritive and medicinal properties (Shrestha, 2004). Onion is the richest source of calcium (47mg), phosphorus (50 mg), vitamin $\mathrm{C}(11 \mathrm{mg})$, carbohydrates $(11.1 \mathrm{mg})$, iron $(0.7 \mathrm{mg})$ and protein $(1.2 \%)$ in every 100 g (Kumar et al., 2010). It also possesses medicinal properties too, by acting as a good appetizer and is with anti-carcinogenic properties. The allyl propyl disulfide present in the onion decreases the diabetes, organo sulfur compounds prevents the cardiovascular diseases and some flavonoids, vitamins and minerals present in onion helps to prevent diseases to human (Ashwini et al., 2014).Onion is grown in temperate and tropical zones either as annual or biannual depending on the cultivated condition. It is generally grown throughout the year with supportive irrigation, but the main planting seasons are June-July and December-January (Shrestha, 2004).

India is the largest producer of onion next to China. The total world production of onion is 74250809 Mega tones (MT equal to billion kilo gram). In India, the area covered under onion is 1285000 ha during 2017-2018 (National Horticultural Board, 2018), and the major onion producing states in a decreasing order are Maharashtra, Madhya Pradesh, Karnataka, Rajasthan, Bihar, Andhra Pradesh, Haryana, West Bengal, Uttar Pradesh and Chhattisgarh which cover nearly $90 \%$ of onion production.
The production and productivity of onion is hampered by the manifestation of pests and diseases. Among the 10 numbers of insect pests reported on onion (Gupta et al., 1998) the leaf feeding insects viz., beet armyworm (Spodoptera exigua) (Hubner), tobacco leaf caterpillar, Spodoptera litura (Fabricius) and American bollworm, Helicoverpa armigera (Hubner), thrips, Thrips tabaci Lindeman etc., are considered a threat to onion cultivation in recent years (Ueno, 2016).

The beet armyworm S.exigua causes extensive damage on onion and even upto $33.4 \%$ damage has been recently recorded (Arulkumar et al., 2017). The H.armigera utilizes onion as a major host and causes heavy economic yield loss (Anonyms, 2014). The high density planting of onion pave the way to attract by the H.armigera (Senan et al., 2011). The tobacco leaf caterpillar, $S$. litura feed on onion leaves and cause minor damage to the onion bulbs also (Ahmad, 2013). The fall armyworm, Spodoptera frugiperda (J. E. Smith) (Noctuidae: Lepidoptera) utilizes onion as an alternative host and causes yield loss up to $5.2 \%$ yield loss. The larva enters into onion tube leaf by scrapping and cutting the leaf tissues and continues feeding (Fernandes et al., 2011, Chormule et al., 2018).

Host plant resistance is one of the component for Integrated Pest Management (IPM), environmental friendly and it is compatible with all pest control method. Food consumption indices or nutritional indices were used for developing the resistant cultivars (Jallow et al., 2004). GR- Growth Rate, CR- Consumption Rate, CIConsumption Index, AD- Approximate digestibility, ECI- Efficiency of Conversion of ingested food, ECD- Efficiency of Conversion of Digested food are the key indices being studied, The growth parameters and nutritional indices varied among different 
host plants of S.litura (Daniel and Samiayyan, 2017) and H.armigera (Hemati et al., 2011). Larval growth, development and its reproduction depends on their host nutrition, quality and quantity (Scriber and Slansky, 1981).

Lepidopteran larval growth rate depends on its nutritive food, if the host does not have more nutritive value means the larva complete its lifecycle shortly (Hwang, 2008).

The ECI is an overall measure of an insect's ability to utilize the food ingested for growth and development, and ECD is a measure of the efficiency of conversion of digested food into growth (Nathan et al., 2005). ECI and ECD showed the significant difference in nutritional indices of caterpillars in utilization of soybean varieties for growth and development (Rahman and Mozini, 2007).

The feeding pattern of the larva varied among different instars like the first two or three instars scrapping the leaves but remaining instars cause defoliation to the leaves. These four leaf feeders cause economical damage to the onion crop. The estimation of food consumption indices is being used to know the feeding potential of leaf feeding insects and also understand which one of the pest prefer onion as most for food and which one cause more damage to the onion. This study provides some new information about onion damaging leaf feeders.

\section{Materials and Methods}

\section{Larval mass culturing}

$S$. exigua, $S$. litura and $H$. armigera were mass cultured using onion leaves, castor leaves and artificial diet (NBAIR-Natural Bureau of Agricultural Insect Resources recommended) respectively under normal room temperature. S.frugiperda larva were field collected maize and onion fields from Agricultural college and Research Institute, Madurai campus, segregated instar wise and used in the experiments. Care was taken that the larva were disease and parasitism free and taken test.

Food consumption, digestion and utilization indices of various larva on onion plant

Mass cultured freshly moulted third instar larvae of $H$. armigera, S. litura, S. exigua and field collected $S$. frugiperda larvae were used for this study. In each treatment was replicated five times. Each replication had three larvae to study consumption, digestion and utilization of onion leaves on fresh weight basis. This experiment was conducted in Completely Randomized Block Design (CRBD) under room temperature $28 \pm 2^{0} \mathrm{C}$ at the Department of Agricultural Entomology, Agricultural College and Research Institute, Madurai. Pre weighed freshly moulted third instar larvae were allowed to feed the pre weighed fresh and clean onion leaves (CO 1). Individual larva of $H$. armigera, S. litura, $S$. exigua and $S$. frugiperda were independently caged in multi cavity trays for. The availability of food was closely monitored and when the larva showed symptoms for moulting, weight of the individual larva, fecal pellet and left out food material were carefully weighed. The same procedure was followed to further fourth and fifth instar larvae also. According to that recorded values GR, CR, CI, ECD, ECI, AD were calculated (Sultani et al., 2015).

\section{Growth rate (GR)}

Weight gained by larvae (mg)

$\mathrm{GR}=$

Duration of feeding period (days)

Growth rate is expressed as mg/day. 


\section{Consumptive rate $(\mathrm{CR})$}

Weight of food eaten (mg)

$\mathrm{CR}=$

Duration of feeding period (days)

It is expressed as $\mathrm{mg} /$ day.

\section{Consumption index (CI)}

Weight of food eaten $(\mathrm{mg})$

$\mathrm{CI}=$

Duration of feeding period (days) $\mathrm{x}$ Mean

weight of larvae during feeding period (mg)

\section{Assimilation efficiency (AE)/ Approximate} digestibility (AD)

Weight of food ingested (mg) - Weight of faeces $(\mathrm{mg}) \times 100$

$\mathrm{AE}=$

Weight of food ingested (mg)

\section{Efficiency of conversion of digested food (ECD)}

The ECD measures the efficiency of conversion of assimilated food to the insect biomass.

Weight gained by larvae (mg)

ECD = -------------- x 100

Weight of food eaten $(\mathrm{mg})$ - Weight of faeces (mg)

Efficiency of conversion of ingested food (ECI)

The ECI measures the overall efficiency of

Conversion of ingested food to insect biomass.

Weight gained by larvae (mg)

ECI = -------- x 100

Weight of food eaten by larvae (mg)

\section{Statistical analysis}

Food Consumption Indices of different larvae reared on single onion host plant were subjected to statistical analysis. The growth parameters like GR, CI and CR were subjected to square root transformation and $\mathrm{AE}, \mathrm{ECI}$ and $\mathrm{ECI}$ were subjected to arcsine transformation. The values were further subjected to one way ANOVA and were analysed using SPSS 17.0.

\section{Results and Discussion}

\section{Growth rate (GR)}

Among the four species of onion leaf feeding caterpillars, S. exigua had the highest GR $(0.08)$ and was followed by S. litura (0.06), $S$.frugiperda (0.05) and $H$. armigera (0.03) in the third instar stage. In the fourth instar stage, the highest GR was recorded in $S$. frugiperda (0.08) followed by $S$. litura (0.06), S. exigua (0.05) and the lowest GR was found on $H$. armigera (0.04). In fifth instar stage, $H$. armigera $(0.08)$ had the highest GR followed by $S$. frugiperda (0.06), S. exigua (0.05), while $S$. litura (0.04) had the lowest GR, Significant difference was observed on third instar of all larvae in GR but fourth and fifth instar of all four larvae were on par with each other (Table 1).

\section{Consumption rate (CR)}

In third instar stage, $S$. exigua had the highest CR (0.82) among the four leaf feeding caterpillars followed by $S$. frugiperda (0.71), $H$. armigera (0.68) and S. litura (0.49). In fourth instar stage, the highest $\mathrm{CR}$ was noticed in $H$. armigera (0.93) followed by S. exigua (0.76), S. frugiperda (0.73) and the lowest food was consumed by S. litura (0.72). In fifth instar, $H$. armigera (0.98) consumed more food followed by $S$. frugiperda (0.79), S. exigua (0.78), while $S$. litura (0.75) 
consumed a less food among four larvae. The $\mathrm{CR}$ of $H$. armigera showed the significant difference among all other larvae in third, fourth and fifth instars. The CR of S. litura showed the significant difference among all other larvae in third and fifth instars but the $\mathrm{CR}$ in fourth instar of $S$. litura was on par with S.frugiperda and S.exigua. No significant difference was observed in S.frugiperda and S.exigua among all instars (Table 2).

\section{Consumption index}

Among the four larvae, the consumption index of third instar was the highest in $S$. frugiperda (8.47) followed by $H$. armigera (8.37), S. exigua (7.91) and the lowest CI was noticed on S. litura (2.99). In fourth instar stage, S.exigua (7.49) had the highest CI followed by $H$. armigera (5.91), S. frugiperda (3.5) and the lowest CI was found on S. litura (2.15).

In fifth instar stage S.exigua had a highest CI (5.08) followed by $H$. armigera (3.55), S.frugiperda (3.54) and the lowest CI was found with $S$. litura (2.35). In third instar no significant difference was observed on S.exigua, S.frugiperda and H.armigera but $S$. litura was significantly different with each other. Fourth and fifth instar of all larvae showed the significant difference with each other (Table 3 ).

\section{Assimilation efficiency (AE) / Approximate digestibility (AD)}

Significant difference in AD was found among the four species of larvae in third to fifth instar stages. The H.armigera had the highest AD (93.31) followed by S.litura (90.31), S.frugiperda (76.62) and the lowest CI was found on S.exigua (88.62) among the four leaf feeding caterpillars in third instar stage. In fourth instar of S. litura (95.0) showed the highest $\mathrm{AD}$ followed by $H$. armigera (92.96), S. exigua (79.44) and the lowest $\mathrm{AD}$ was found in $S$. frugiperda (79.04). In fifth instar stage, the highest AD was found in H. armigera (94.77) followed by S. litura (90.41), S. frugiperda (78.57) and the lowest AD was noticed on $S$. exigua (73.71) (Fig. 1).

In a stage of instar, means indicated by bars with the same alphabet are statistically not significantly different by ANOVA.

\section{Efficiency of conversion of digested food (ECD)}

Among the four leaf feeding caterpillars, in third instar stage, the ECD into body matter was the highest in S. litura (12.76) followed by S.exigua (11.03), S.frugiperda (8.96) and significantly the lowest ECD was observed in $H$. armigera (5.23) In fourth instar stage, S.frugiperda (13.49) had significantly the highest ECD followed by S.exigua (9.56), $S$. litura (9.44) and the lowest ECD was found on $H$. armigera (5.18).

In fifth instar stage, S.exigua (9.56) had the highest ECD followed by S.frugiperda (9.34), $H$. armigera (8.04) and S. litura (6.17) had the lowest ECD in fifth instar stage.

The S. litura had significantly the highest ECD in third and fourth instar but fifth instar showed the lowest ECD.

All larvae of fifth instar stage were on par with each other. Significant difference was noticed in third instar larvae of $H$. armigera and S. litura but S.exigua and S.frugiperda were on par. No significant difference was observed in $S$. litura, S.exigua and S.frugiperda in fourth instar stage (Fig. 2).

In a stage of instar, means indicated by bars with the same alphabet are statistically not significantly different by ANOVA. 
Table.1 Growth rate of four different lepidopteran species larvae at three different instar stages on onion A, cepa var aggregatum leaves as a source of food

\begin{tabular}{|l|l|l|l|l|}
\hline \multirow{2}{*}{ Treatment } & \multicolumn{3}{|c|}{ Growth Rate* } & \multirow{2}{*}{ Total Mean } \\
\cline { 2 - 4 } & Third instar & Fourth instar & Fifth instar & \\
\hline Helicoverpa armigera & 0.03 & 0.05 & 0.07 & 0.05 \\
& $(0.18)^{\mathrm{d}}$ & $(0.21)^{\mathrm{c}}$ & $(0.27)^{\mathrm{a}}$ & $(0.23)$ \\
\hline Spodoptera litura & 0.06 & 0.07 & 0.04 & 0.06 \\
& $(0.249)^{\mathrm{b}}$ & $(0.26)^{\mathrm{ab}}$ & $(0.20)^{\mathrm{b}}$ & $(0.24)$ \\
\hline S.exigua & 0.08 & 0.05 & 0.05 & 0.06 \\
& $(0.28)^{\mathrm{a}}$ & $(0.23)^{\mathrm{bc}}$ & $(0.23)^{\mathrm{ab}}$ & $(0.25)$ \\
\hline S.frugiperda & 0.05 & 0.08 & 0.06 & 0.06 \\
& $(0.21)^{\mathrm{c}}$ & $(0.28)^{\mathrm{a}}$ & $(0.24)^{\mathrm{ab}}$ & $(0.25)$ \\
\hline
\end{tabular}

*Mean of five replication

In a column, means followed by the same alphabet are not statistically significantly different by ANOVA.

Table.2 Consumption rate of four different lepidopteran species larvae at three different instar stages on onion A, cepa var aggregatum leaves as a source of food

\begin{tabular}{|c|c|c|c|c|c|}
\hline & Treatment & & isumption $\mathbf{R a}$ & & Total \\
\hline & & Third instar & Fourth instar & Fifth instar & mean \\
\hline 1 & Helicoverpa armigera & $\begin{array}{l}0.68 \\
(0.83)^{b}\end{array}$ & $\begin{array}{l}0.93 \\
(0.97)^{\mathrm{a}}\end{array}$ & $\begin{array}{l}0.98 \\
(0.99)^{\mathrm{a}}\end{array}$ & $\begin{array}{l}0.87 \\
(0.93)\end{array}$ \\
\hline 2 & Spodoptera litura & $\begin{array}{l}0.49 \\
(0.70)^{c}\end{array}$ & $\begin{array}{l}0.72 \\
(0.85)^{b}\end{array}$ & $\begin{array}{l}0.75 \\
(0.86)^{c}\end{array}$ & $\begin{array}{l}0.65 \\
(0.81)\end{array}$ \\
\hline 3 & Spodoptera exigua & $\begin{array}{l}0.82 \\
(0.90)^{\mathrm{a}}\end{array}$ & $\begin{array}{l}0.76 \\
(0.87)^{b}\end{array}$ & $\begin{array}{l}0.78 \\
(0.88)^{b}\end{array}$ & $\begin{array}{l}0.78 \\
(0.89)\end{array}$ \\
\hline 4 & Spodoptera frugiperda & $\begin{array}{l}0.71 \\
(0.84)^{b}\end{array}$ & $\begin{array}{l}0.73 \\
(0.85)^{b}\end{array}$ & $\begin{array}{l}0.79 \\
(0.89)^{b}\end{array}$ & $\begin{array}{l}0.74 \\
(0.86)\end{array}$ \\
\hline
\end{tabular}

*Means of five replication

In a column, means followed by the same alphabet are statistically not significantly different by ANOVA.

Table.3 Consumption Index of four different lepidopteran species larvae at three different instar stages on onion $A$, cepa var aggregatum leaves as a source of food

\begin{tabular}{|l|l|l|l|l|l|}
\hline \multirow{2}{*}{} & \multirow{2}{*}{ Treatment } & \multicolumn{3}{|c|}{ Consumption Index* } & \multirow{2}{*}{ Total mean } \\
\cline { 3 - 5 } & & Third instar & Fourth instar & Fifth instar & \\
\hline $\mathbf{1}$ & \multirow{2}{*}{ Helicoverpa armigera } & 8.37 & 5.91 & 3.55 & 5.94 \\
& & $(2.89)^{\mathrm{a}}$ & $(1.43)^{\mathrm{b}}$ & $(1.88)^{\mathrm{b}}$ & $(2.44)$ \\
\hline $\mathbf{2}$ & \multirow{2}{*}{ Spodoptera litura } & 2.99 & 2.15 & 1.67 & 2.27 \\
& & $(1.73)^{\mathrm{b}}$ & $(1.47)^{\mathrm{d}}$ & $(1.29)^{\mathrm{d}}$ & $(1.51)$ \\
\hline $\mathbf{3}$ & \multirow{2}{*}{ Spodopteraexigua } & 7.91 & 7.49 & 5.08 & 6.82 \\
& & $(2.81)^{\mathrm{a}}$ & $(2.74)^{\mathrm{a}}$ & $(2.25)^{\mathrm{a}}$ & $(2.61)$ \\
\hline $\mathbf{4}$ & \multirow{2}{*}{ Spodopterafrugiperda } & 8.47 & 3.54 & 2.35 & 4.79 \\
& & $(2.91)^{\mathrm{a}}$ & $(1.88)^{\mathrm{c}}$ & $(1.53)^{\mathrm{c}}$ & $(2.19)$ \\
\hline
\end{tabular}

Means of five replication.

In a column, means followed by the same alphabet are statistically not significantly different by ANOVA. 
Fig.1 Assimilation efficiency of four different lepidopteran species larvae at three different instar stages on onion A, cepa var aggregatum leaves as a source of food

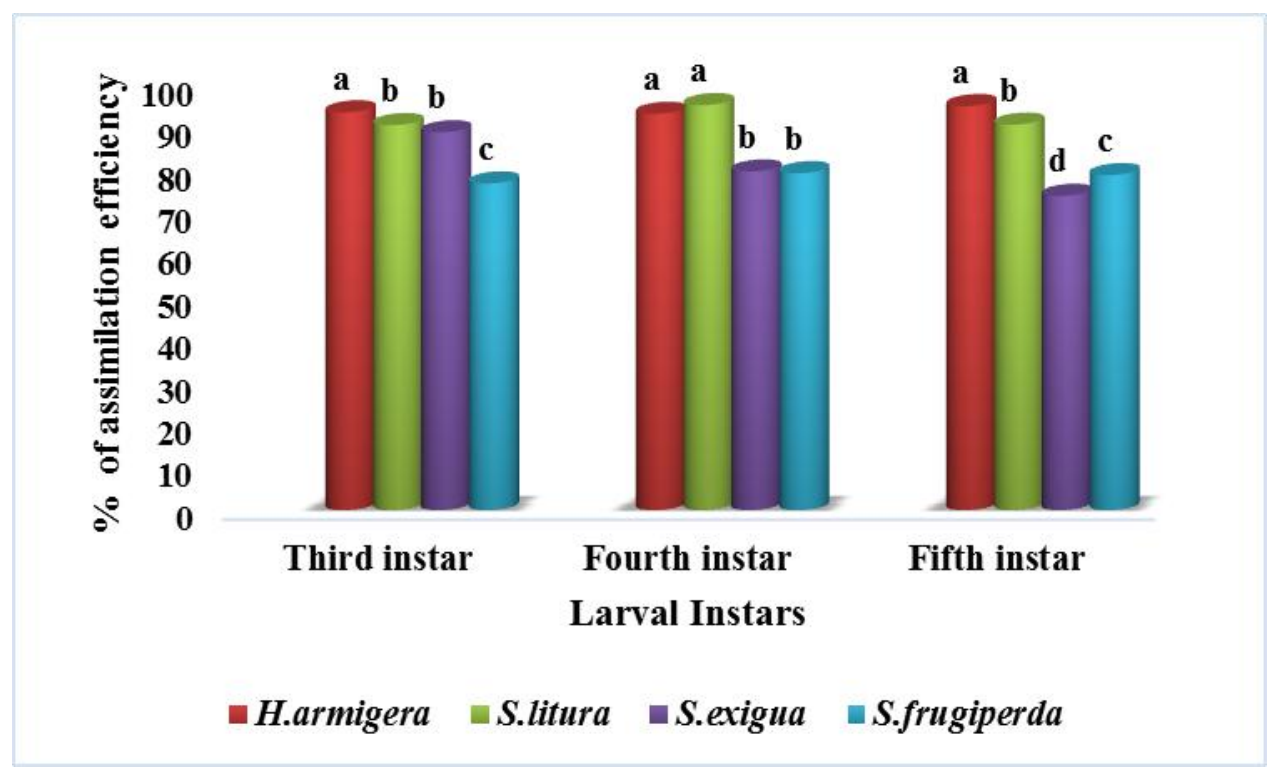

Fig.2 Efficiency of conversion digested food (ECD) of four different lepidopteran species larvae at three different instar stages on onion A, cepa var aggregatum leaves as a source of food

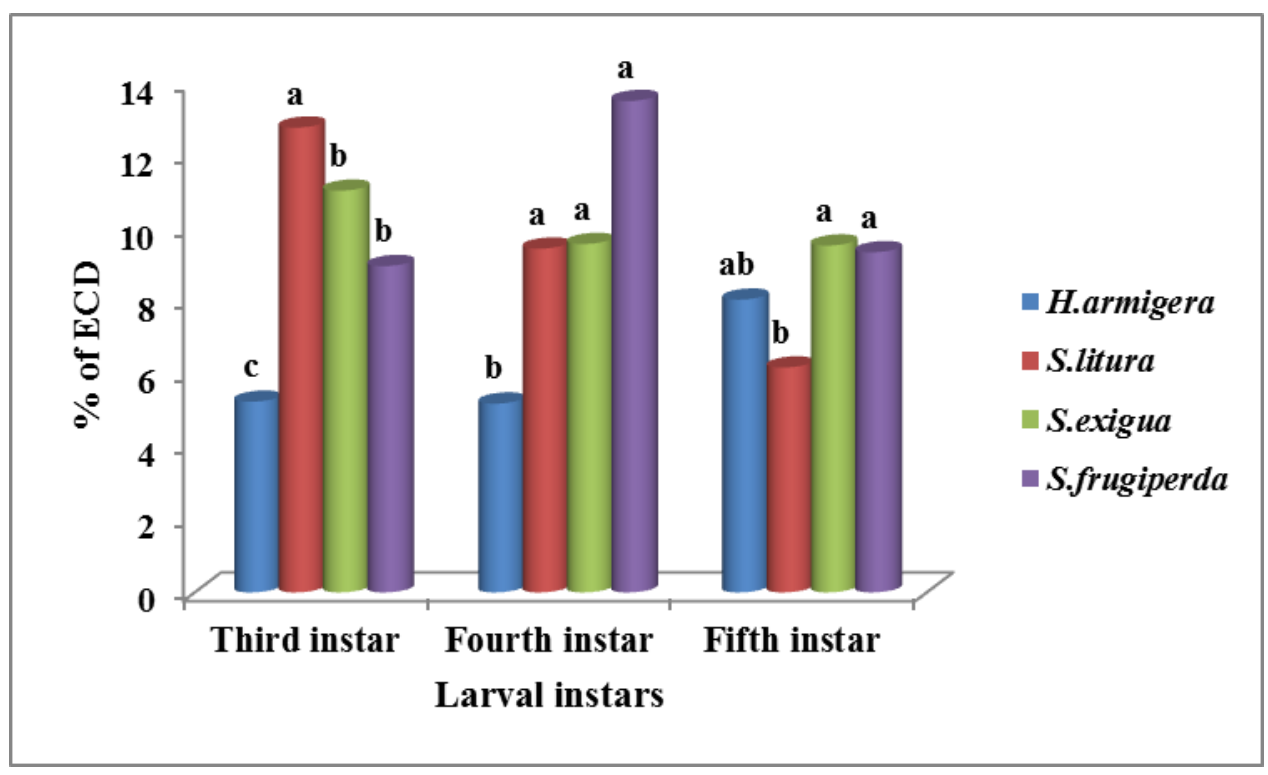


Fig.3 Efficiency of Conversion of ingested food (ECI) of four different lepidopteran species larvae at three different instar stages on onion A.cepa var aggregatum leaves as a source of food

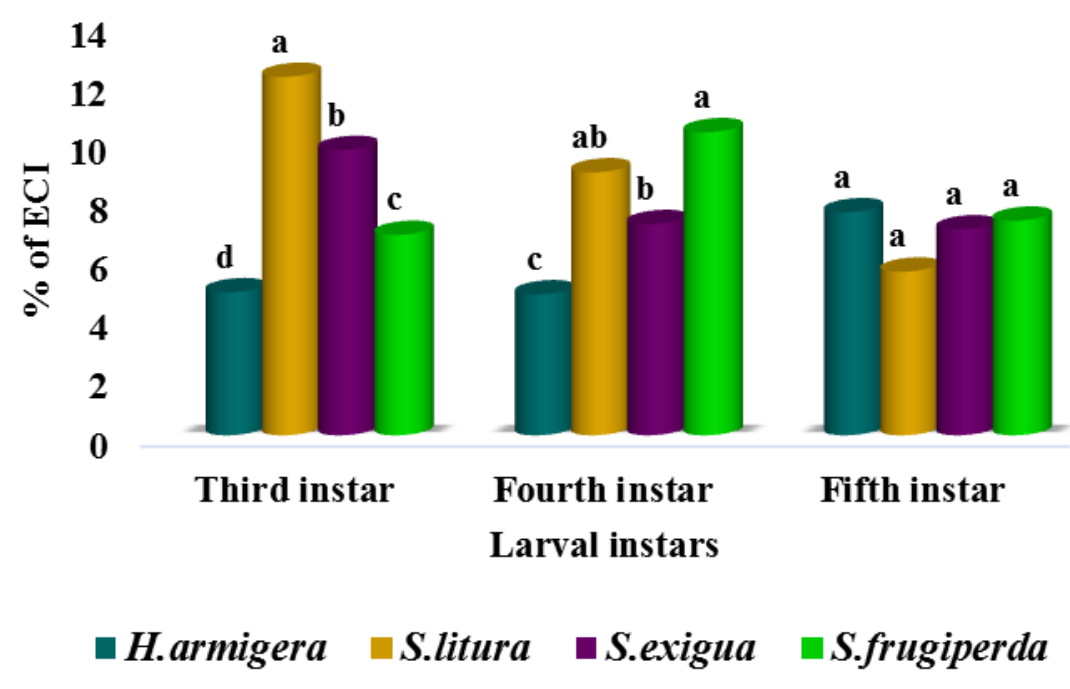

Efficiency of Conversion of ingested food (ECI)

The ECI into body mass had significantly varied among the four species of larvae.

The S.litura had significantly the highest ECI (12.23) followed by S.exigua (9.74), S.frugiperda (6.84) and significantly the lowest ECI was noticed in H.armigera (4.88241) in third instar stage. In fourth instar, significantly the highest ECI was found with S.frugiperda (10.35) and was followed by S.litura (8.98) and S.exigua (7.21), while the lowest ECI was observed in H.armigera (4.81).

The H.armigera had the highest ECI (7.61) followed by S.frugiperda (7.3), S.exigua (7.03) and the lowest ECI was observed in S.litura (5.59) among the four leaf feeding caterpillars in fifth instar stage, however with no significant difference among them (Fig. 3).

In a stage of instar, means indicated by bars with the same alphabet are statistically not significantly different by ANOVA.
The body weight is an important indicator of fitness of insect (Liu et al., 2004). Whenever, the insects are encountering low quality food, it reduces all aspects of the feeding insects and creates challenge for the herbivore upon restriction to access alternative food sources (Augner, 1995) The larval weight gain is influenced by on the type of host plants utilized by the larvae. Under natural conditions, for the presence of suboptimal food conditions, herbivores are constantly confronted with deficiency of essential nutrients in plant tissues (Mattson, 1980; Plath and Boersma, 2001) and as such the chronic ingestion of low-quality food reduces nearly all aspects of herbivore performance (Lundberg and Åström, 1990).

In order to meet and compensate the deficits in food quality, many herbivores have developed a highly conserved compensatory mechanism by increasing the rate of food consumption (Simpson, and Simpson, 1990). The larval weight of H.armigera was more on chickpea than tomato meskin The S.litura and H.armigera showed the different growth parameters when fed with the same plant of 
chickpea (Naseri et al., 2010). The H.armigera had a lower ECI (9.22\%) and ECD (10.67\%) when compared to S.litura that had a higher ECI $(11.31 \%)$ and ECD (12.45\%) (Daniel and Samiayyan, 2017). In our study the onion feeding S.litura showed the highest ECI (8.93\%) and ECD (9.46\%) than H.armigera's ECD $(6.15 \%)$ and ECI $(5.77 \%)$. The ECD and ECI values of H.armigera were significantly different among different host plant consumption (Hemati et al., 2011) but less significant difference was observed in our study on onion feeding larvae and the fifth instar showed no significant difference among them.

The ECD and ECI values varied from 14.16 and $2.24 \%$ to $12.55 \%$ when S.exigua had fed soybean varieties (Mehrkhou, 2013) but in the present study, onion fed S.exigua showed the ECI of $7.03 \%$ to $9.74 \%$ and ECD of $9.52 \%$ to $11.03 \%$. Thevalues of ECI is a common measurement of insects' ability to use the consumed food for growth and development. The S.frugiperda showed the ECD (5.2\% to $29.5 \%)$ and ECI (1.8\% to $4.5 \%)$ values when fed with sorghum plant but in this study, the onion fed S.frugiperda larvae showed much greater ECD $(8.95 \%$ to $13.49 \%)$ and ECI $(6.84 \%$ to $10.35 \%)$ values indicating that onion may act as a good host plant for S.frugiperda.

The ECD is an index of the efficiency of conversion of digested food into growth (Naseri et al., 2011). Change in ECD also indicates the overall increase or decrease of the proportion of digested food metabolized for energy. Therefore, no change in ECI and ECD values indicate that ingested secondary biochemicals do not exhibit any chronic toxicity (Koul et al., 2004) to the utilizing larvae.

The food consumption was less means, the food go down slowly on the digestive system and the food was completely converted into nutrients or else the food have high nutritive value because of that they consume less food (Soo hoo and Fraenkel, 1966). The quality of host plant is associated with herbivore suitability including physical attributes, allelochemicals and/or nutritional composition (Mattson and Scriber, 1987; Hasan and Ansari, 2010).

The quality of host plant describes the component of food which includes both absolute and relative amounts of proteins, amino acids, lipids, fatty acids, carbohydrates, water, minerals and vitamins, in which positively or negatively affect the performance of herbivorous insects (Sharma et al., 1982; Yazdanfer et al., 2015). In the present study, among the four different generalist caterpillars that were forcefully fed with aggrgatum onion leaves as food, fifth instar stadium $S$. litura larvae showed reduced ECD than the other species, whereas H.armigera larvae showed lower ECD and ECI at third and fourth instar stages. While S.frugiperda and $S$. exigua larvae showed higher ECD in all the three instar stages of their growth indicating that these insects are very well utilizing the onion as a host plant and warranting management practices.

\section{References}

Anonymous. 2017. Horticultural Statistics at a Glance 2017. Horticulture Statistics Division Department of Agriculture, Cooperation and Farmers Welfare Ministry of Agriculture and Farmers Welfare Government of India. 514p.

Arulkumar G, Manisegaran S, Nalini R and Mathialagan M. 2017. Seasonable abundance of beet armyworm Spodoptera exigua (Hubner) infesting Onion with weather factors in Madurai district of Tamil Nadu. Journal of Entomology and Zoology Studies, 5(6): 1157-1162.

Ashwini M and Sathishkumar R. 2014. Onion 
(Allium cepa) - Ethnomedicinal and therapeutic properties. Handbook of Medicinal Plants and their Bioactive Compounds, 27-34.

Augner, M. (1995). Low nutritive quality as a plant defence: effects of herbivoremediated interactions. Evolutionary Ecology, 9, 605-616. doi: https://doi.org/10.1007/BF01237658.

Barcelos L.M., O Fabrício O. Fernandes, Caroline Lopes, Beatriz M. Emygdio, Ricardo Valgas, Indyra F. de Carvalho and Ana Paula S. A. da Rosa. 2019. Biology and Nutritional Indexes of Spodoptera frugiperda (Lepidoptera: Noctuidae) in Saccharine Sorghum. Journal of Agricultural Science, 11, No. 4.

Chormule. A., Naresh Shejawal, Sharanabasappa, CM Kalleshwaraswamy, R. Asokan and HM Mahadeva Swamy. 2018. First report of the fall Armyworm, Spodoptera frugiperda (J. E. Smith) (Lepidoptera, Noctuidae) on sugarcane and other crops from Maharashtra, India. Journal of Entomology and Zoology Studies, 7(1): 114-117.

Daniel. D.J. and Samiayyan K.2.2017. Growth parameter indices of cut worm larva spodoptera litura (fab.) on various host plants. International Journal of Agriculture Sciences, 9(29): 4372-4376

Fernandes. F. L. Fernandes, Juno F. S. Diniz, Flávia M. Alves and Luiz O. D. Silva. 2011. Injury and Spatial Distribution of Spodoptera frugiperda (J. E. Smith) (Lepidoptera: Noctuidae) in Onion Allium cepa (Alliaceae) in Alto Paranaíba, Minas Gerais, Brazil. Entomological News.

Hasan, F., and Ansari, M. S. (2010). Effect of different cole crops on the biological parameters of Pieris brassicae (L.)(Lepidoptera: Pieridae) under laboratory conditions. Journal of Crop Science and Biotechnology, 13(3): 195202. doi: 10.1007/s12892-010-0025-2.

Hematia S.A., B. Naserib, G. Nouri Ganbalanic, H. Rafiee Dastjerdid, and A. Golizadehe. 2011. Effect of different host plants on nutritional indices of the pod borer, Helicoverpa armigera. Journal of Insect Science, 12.

Hoo S.C.F. and G. Fraenkelt. 1966. The consumption, digestion and utilization of food plants by a polyphagous insect, Prodenia eridania (Cramer). Journal of Insect Physiology, 12: 711-730.

Hwang SY, Liu C.H, Shen T.C., 2008. Effects of plant nutrient availability and host plant species on the performance of two Pieris butterflies (Lepidoptera: Pieridae). Biochemical Systematics and Ecology, 36:505-513.

Jallow MFA, Paul Cunningham J, Zalucki MP. 2004. Intra-specific variation for host plant use in Helicoverpa armigera (Hubner) (Lepidoptera: Noctuidae): implications for management. Crop Production Services, 23: 955-964.

Koul O, Singh G, Sing R, Singh J. 2004. Bioefficacy and mode-of-action some limonoids of salanin group from Azadirachta indica a. Juss and their role in a multicomponent system against lepidopteran larvae. Journal of Bioscience, 29: 409-416.

Kumar K.P.S., Debjit Bhowmik, Chiranjib, Biswajit and Pankaj Tiwari. 2010. Allium cepa: A traditional medicinal herb and its health benefits. Journal of Chemical and Pharmaceutical Research, 2(1): 283-291.

Liu Z.D., Li D.M., Gong P.Y., Wu K.J. 2004. Life table studies of the cotton bollworm, Helicoverpa armigera (Hübner) (Lepidoptera: Noctuidae), on different host plants. Environmental Entomology, 33: 1570-1576.

Lundberg, P., and Astrom, M. (1990). Low nutritive quality as a defense against optimally foraging herbivores. The American Naturalist, 135(4), 547-562.

Mattson, W. (1987). Nutritional ecology of insect folivores of woody plants: nitrogen water, fiber, and mineral considerations. Nutritional ecology of insects mites spiders, and related invertebrates, 105146.

Mattson, W. J. (1980). Herbivory in relation to 
plant nitrogen content. Annual Review of Ecology, Evolution, and Systematics, 11: 119-161.

Mehrkhou. F. 2013. Effect of soybean varieties on nutritional indices of beet armyworm Spodoptera exigua (Lepidoptera: Noctuidae). African Journal of Agricultural Research, 8(16): 1528-1533.

Naseri B, Fathipour Y, Moharramipour S, Hosseininaveh V. 2009. Comparative life history and fecundity of Helicoverpa armigera (Lepidoptera: Noctuidae) on different soybean varieties. Entomological Science, 12(2): 147-154.

Nathan S.S., Chung P.G., Murugan K. 2005. Effect of biopesticides applied separately or together on nutritional indices of the rice leafolder Cnaphalocrocis medinalis. Phytoparasitica, 33: 187-195.

Plath, K., and Boersma, M. (2001). Mineral limitation of zooplankton: stoichiometric constraints and optimal foraging. Ecology, $\quad$ 82(5): 1260-1269. doi:https://doi.org/10.1890/00129658(200 1)082[1260:MLOZSC]2.0.CO;2

Rahman A.H.R., Al-Mozini R.N. 2007. Antifeedant and toxic activity of some plant extracts against larvae of cotton leafworm Spodoptera littoralis (Lepidoptera: Noctuidae). Pakistan Journal of Biological Science. 10: 44674472.

Scriber J.M., Slansky F. 1981. The nutritional ecology of immature insects. Annual Review of Entomology, 26: 183-211.

Sharma, H., Aarwal, R., and Singh, M. (1982).
Effect of some antibiotic compounds in cotton on post-embryonic development of spotted bollworm (Earias vittella F.) and the mechanism of resistance in Gossypium arboreum. Proceedings: Animal Sciences, 91(1), 67-77. doi: 10.1007/BF03186061.

Shrestha, H, 2007. A Plant Monograph on Onion (Allium cepa L.). The School of Pharmaceutical and Biomedical Sciences, Pokhara University, Simalchaur, Pokara, 7(8): 57.

Simpson, C., and Simpson, S. (2017). The mechanisms of nutritional compensation by phytophagous insects. In E. A. Bernays (Ed.), Insect-Plant Interactions (1990) (pp. 111-160): CRC Press.

Sultani. M. S, Ram Singh and S. K. Dhankhar. 2015. Okra Genotypes Affecting Performance of Shoot and Fruit Borer Earias vittella (Fabricius) (Noctuidae: Lepidoptera).

Vaddoria, M.A. and Ganesh Kulkarn. 2017. Onion. Biodiversity in horticultural crops. Vol.6.

Yazdanfar, H., Daryaei, M. G., Sendi, J. J., Ghobari, H., and Valizadeh, B. (2015). Effects of various host plants on nutritional indices and some biochemical compounds in green oak leaf roller, Tortrix viridana L. (Lepidoptera: Tortricidae). Journal of Entomological and Acarological Research, 47(3), 98102. doi: 10.4081/jear.2015.4954

\section{How to cite this article:}

Rubiya, R., M. Murugan, M. Shanthi, V. Krishnamoorthi and Vellaikumar, S. 2019. Comparative Feeding and Digestive Performance of Four Lepidopteran Species of Larvae on Onion, Allium cepa var aggregatum L. as A Host Plant. Int.J.Curr.Microbiol.App.Sci. 8(06): 1692-1702. doi: https://doi.org/10.20546/ijcmas.2019.806.202 